\title{
EMC Evaluation of Off-Grid and Grid-Tied Photovoltaic Systems for the Brazilian Scenario
}

\author{
H. J. Loschi, L. A. S. Ferreira, D. A. Nascimento, P. E. R. Cardoso, S. R. M. Carvalho, and F. D. Conte
}

\begin{abstract}
In this paper is discussed the importance of analysis for electromagnetic compatibility of the photovoltaic generation systems components concerning emissions of radiated and conducted electromagnetic disturbances on mains DC and AC lines. Current standards and tests showed that some frequency spectrum bands such from $150 \mathrm{kHz}$ to $5 \mathrm{MHz}$ it is the more affected by conducted disturbances and from $30 \mathrm{MHz}$ to $200 \mathrm{MHz}$ it is the more affected by radiated disturbances, by the two main types of photovoltaic generation systems: Grid-Tied and Off-Grid applications. The concern is greater since one equipment used for the tests has EMC certifications. In addition, with the measurements of radiated and conducted electromagnetic disturbances it becomes possible to discuss a future scenario for mandatory certification of components of PV generation systems, mainly PV inverters and their applications.
\end{abstract}

Index Terms-Electromagnetic compatibility, DC-AC power conversion, Photovoltaic power systems.

\section{INTRODUCTION}

In recent years solar energy has become more and more widely used, and the requirements for photovoltaic (PV) system components regarding electromagnetic disturbances on AC (alternating current) and DC (direct current) lines has led to many new improvements and suggestions regarding the test setup and applicable limits [1].

Electromagnetic compatibility (EMC) test program it has been developed at several PV generation systems for Grid-Tied, Off-Grid and Hybrid applications. Among others was shown that a significant share of PV system components currently available on the market produce signals at radio frequencies (RF) above the limits for household devices.

A source of interference are radio frequency signals on DC lines from PV inverters which may lead to significant radiated electromagnetic fields [2]-[4].

This paper introduces an investigation with respect to emissions (radiated and conducted disturbances on mains DC and $\mathrm{AC}$ lines) and present tests performed at PV inverters for Grid-Tied and Off-Grid applications.

In this context, the paper presented divided into seven sections. In the section two, a general view of the electromagnetic environment a presented. After that in the section three, a basic antenna theory is shown, explaining why

Manuscript received May 25, 2017; revised August 7, 2017.

The authors are with the Department of Communication, Faculty of Electrical and Computer Engineering at Unicamp (DECOM-FEEC-UNICAMP), Campinas 13315-000, SP-Brazil (e-mail hermes@decom.fee.unicamp.br, perc@decom.fee.unicamp.br, eng.douglas.a@ieee.org srcmessias@gmail.com,fd.conte@decom.fee.unicamp.br).
PV generation system installations can be particularly dangerous and in the section four, analysis of PV generation systems structure is made. Section five presenting the measurement set-up and the section six an analysis and discussion of the tests results of conducted and radiated disturbances. Finally, in the section seven a conclusion with some recommendation of these EMC issues and the Brazilian certification scenario is presented. Up recognizing the very different perspectives and priorities of individuals and organizations involved, the authors propose a broad analysis to examine the different ways for certification of EMC issues.

\section{ELECTROMAGNETIC ENVIRONMENT}

The electromagnetic environment (EME) may be defined as follows [5]: The electromagnetic environment is the totality of all electromagnetic phenomena existing at a certain location. It is describable by [6]:

- listing and characterizing the interference sources and quantities at the considered location;

- listing and characterizing specialties of the installation, documentation of possible and realized EMC-measures;

- listing and characterizing of EMC-relevant non-electric environmental conditions (e.g. humidity, triboelectricity). In this environment, electronic devices must work as specified without burdening the environment over a certain measure. Electromagnetic interference (EMI) sources can be classified into several categories [7]. These classification may be done according to the source (natural or man-made), according to broad band or narrow band sources, according to coherent or incoherent sources, or according to several other categories [6].

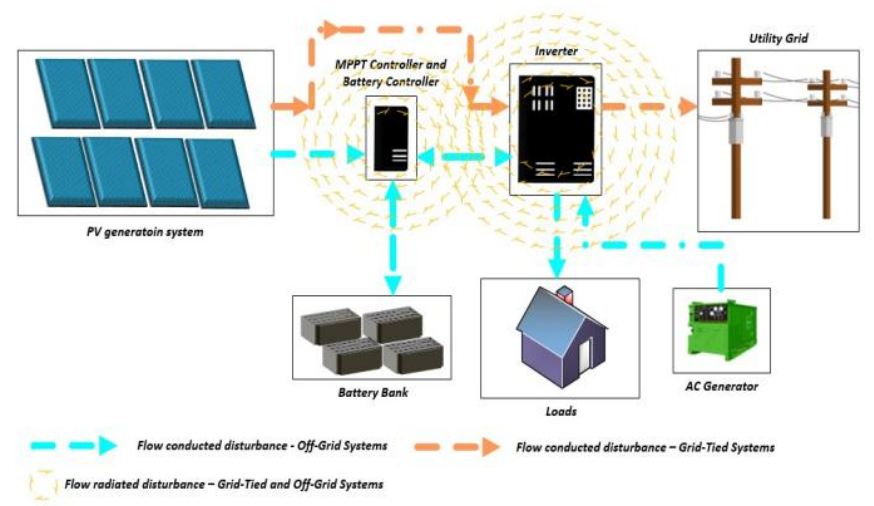

Fig. 1. Illustration of the coupling paths between a grid connected with hybrid PV system, with the flow of conducted and radiated disturbances for both operations modes: Off-Grid and Grid-Tied.

The EME has to be analyzed in particular for any PV generation system. Fig. 1 gives an overview of the potential 
coupling paths between a grid connected with hybrid PV system, with the flow of conducted and radiated disturbances for both operations modes: Off-Grid and Grid-Tied.

\section{BASIC ANTENNA THEORY}

Antenna is a transition device, or transducer, between a guided wave and a free-space wave, or vice versa [8]. In other words, antenna converts electromagnetic waves into electric current, or back. It is used for transmission or reception of electromagnetic waves at radio frequencies as a mandatory part of any radio. Antenna is used in radio and television broadcasting, radio communications, cellular phones, radars, and more. However antennas are not always intended, sometimes electrical systems create unintended antennas fields.

Intended antenna. Intended antenna is used to produce / receive defined electromagnetic wave. Typical applications in this case following: radio antennas, microwave applications (Industrial, Medical, Scientific) and electromagnetic sensors, probes.

There are two types of unintended antennas - active and passive.

Active unintended antenna. Active unintended antennas appear when electromagnetic waves are emitted as unintentional side effect. It can happen in many cases, for example [8]:

- any cable / installed with an alternating electric current;

- any slot / open to the device's screen conductive RF.

- Passive unintended antenna. Passive unintended antennas are any interference in the transmission medium of the electromagnetic waves, for example [8]:

- regular (e.g., mast antenna or cable transmission lines);

- time variable (for example, a windmill or helicopter propellers);

- transitional (e.g., aircraft, missiles).

Typically, PV generation systems represent many PV panel connected in different topologies. The length of the cables connecting the PV panel with each other and with an inverter may be comprises the tens of meters. This current-carrying conductor can work as active unintended antennas in the radio frequency range. For this approach, simple assumption can be made. This assumption is that the conductor connecting the inverter to a PV panel is a Beverage antenna. The Table I shows the values for different frequencies of their wavelength and length of the antenna, which is reasonable to these frequencies.

TABLE I: WAVELENGTH IN DIFFERENT FREQUENCY RANGE [9]

\begin{tabular}{|c|c|c|}
\hline Frequency & Wavelength [meters] & Antenna length [meters] \\
\hline $3-30 \mathrm{~Hz}$ & $10^{8}-10^{7}$ & $10^{8}-10^{7}$ \\
\hline $30-300 \mathrm{~Hz}$ & $10^{7}-10^{6}$ & $10^{7}-10^{6}$ \\
\hline $300-3000 \mathrm{~Hz}$ & $10^{6}-10^{5}$ & $10^{6}-10^{5}$ \\
\hline $3-30 \mathrm{kHz}$ & $10^{5}-10^{4}$ & $10^{5}-10^{4}$ \\
\hline $30-300 \mathrm{kHz}$ & $10^{4}-10^{3}$ & $10^{4}-10^{3}$ \\
\hline $300-3000 \mathrm{kHz}$ & $10^{3}-100$ & $10^{3}-100$ \\
\hline $3-30 \mathrm{MHz}$ & $100-10$ & $100-10$ \\
\hline $300-3000 \mathrm{MHz}$ & $10-1$ & $10-1$ \\
\hline $300-3000 \mathrm{MHz}$ & $1-0.1$ & $1-0.1$ \\
\hline $3-30 \mathrm{GHz}$ & $0.1-0.01$ & $0.1-0.01$ \\
\hline $30-300 \mathrm{GHz}$ & $0.01-0.001$ & $0.01-0.001$ \\
\hline
\end{tabular}

In the conventional PV generation systems the length of cables connecting PV panel with inverter are hundreds of meters, therefore, the most significant interference may be at the frequency range $30-300 \mathrm{kHz}-300-3000 \mathrm{MHz}$. Typical limits for the frequencies and their principal use is taken from [8] and shown in Table II.

TABLE II: PRINCIPAL USE OF DIFFERENT FREQUENCY RANGE [9]

\begin{tabular}{|c|c|c|}
\hline Name & Frequency & Principal use \\
\hline $\begin{array}{l}\text { ELF (Extre. Low } \\
\text { Frequency) }\end{array}$ & $3-30 \mathrm{~Hz}$ & \multirow[t]{3}{*}{ Power grids } \\
\hline $\begin{array}{l}\text { SLF (Super - Low } \\
\text { Frequency) }\end{array}$ & $30-300 \mathrm{~Hz}$ & \\
\hline $\begin{array}{l}\text { ULF (Ultra - Low } \\
\text { Frequency) }\end{array}$ & $300-3000 \mathrm{~Hz}$ & \\
\hline $\begin{array}{l}\text { VLF (Very - Low } \\
\text { Frequency) }\end{array}$ & $3-30 \mathrm{kHz}$ & Submarines \\
\hline LF (Low Frequency) & $30-300 \mathrm{kHz}$ & Beacons \\
\hline MF (Medium Frequency) & $300-3000 \mathrm{kHz}$ & AM broadcast \\
\hline HF (High Frequency) & 3-30 MHz & $\begin{array}{l}\text { Shortwave } \\
\text { broadcast }\end{array}$ \\
\hline $\begin{array}{l}\text { VHF (Very High } \\
\text { Frequency) }\end{array}$ & $\begin{array}{l}300-3000 \\
\mathrm{MHz}\end{array}$ & FM, TV \\
\hline $\begin{array}{l}\text { UHF (Ultra High } \\
\text { Frequency) }\end{array}$ & $\begin{array}{l}300-3000 \\
\mathrm{MHz}\end{array}$ & $\begin{array}{l}\text { LAN, cellular, } \\
\text { GPS }\end{array}$ \\
\hline $\begin{array}{l}\text { SHF (Super High } \\
\text { Frequency) }\end{array}$ & 3-30 GHz & Radar, GSO, data \\
\hline $\begin{array}{l}\text { EHF (Extre. High } \\
\text { Frequency) }\end{array}$ & $30-300 \mathrm{GHz}$ & Radar, automotive \\
\hline
\end{tabular}

This simple approach shows that applications such as AM broadcast, shortwave broadcast, FM, TV, beacons can be interference by disturbances produced by PV generation systems. Interferences influencing shortwave broadcast and beacons look particularly dangerous because they are used to communicate with merchant ships and aircraft. Of course, these obstacles are not dangerous if PV generation systems are in the rural locality, but often they are close to airports or placed on the building roofs which can be dangerous.

\section{ANAlysis of PhOtovoltaic Systems COMPONENTS}

The PV system contains several subsystems, components and other auxiliary. The main devices of any PV system in EMC point of view are: PV cells, inverter, battery controller and cables.

PV cells are compounded in PV panels. These PV panels are grouped in arrays. DC-side of PV generation system consists of several strings. String is PV panels connected in series or parallel. The arrays are in a PV generation system side, the output of units connected with an inverter. The inverters are connected together in parallel and this structure is connected to the switchboard on AC side. Output of switchboard on AC side is connected to line frequency transformer [9]. EMI evaluation of PV generation system is a very difficult task. First, equivalent circuit with elements of PV generation system, both the AC and DC side will be analyzed, this circuit helps to show at what causes the problem [9]. In EMC point of view RF behavior of DC side of a PV system mainly depends on two factors: PV Generator system capacitance and DC lines inductance.

Electromagnetic disturbances are generated in the inverter due to switching actions and clock signals. They propagate as voltages and currents respectively along the DC lines. Since the DC lines may extend for several meters, they represent 
inductance. The PV generator system represents a capacitance due to the large area of the PV panels, and both together results in a resonant circuit for several frequencies. The longer the DC lines and the larger the PV generator system, the lower is the resonance frequency, thus the cable-generator configuration acts as an antenna and electromagnetic fields is generated in the EME. The original line conducted disturbances are "transformed" into radiated disturbances [6], [10].

PV generator system is a large area covered by PV panels; therefore, it represents a capacitance toward the earth or, "earth capacitance". This capacitance usually depends on several factors: size of the panel, height above the ground and relative humidity. Typical values of capacitance have been presented in this investigations and for large ungrounded system are shown in Table III [11].

TABLE III: EARTH CAPACITANCE OF PV UNGROUNDED SYSTEMS [4]

\begin{tabular}{|l|l|}
\hline Conditions & Capacitance \\
\hline Glass-faced panels & $50-150 \mathrm{nF} / \mathrm{kW}_{\text {peak }}$ \\
\hline Thin-film panels & Up to $1 \mu \mathrm{F} / \mathrm{kW}_{\text {peak (damp environments or rainy days) }}$ \\
\hline
\end{tabular}

The size of PV generation systems may extend over some residences or hectares. Therefore, DC lines may extend in length up to $150 \mathrm{~m}$, long lines increase the distributed transversal capacitance effect. Grounding of the PV panel's frames is a very interesting question because it affects not only in EMC aspects but also it influences personnel protection and property protection [4].

Another interesting question is the shielding of DC lines. A shielding of the DC lines may reduce electromagnetic fields significantly, but only in case that the shield is grounded on both sides with (from an RF point of view) a very good connection to earth. Also, shielded DC lines grounded on both sides are the best choice for optimal lightning protection [12].

In DC lines point of view, cabling length affects not only the distributed transversal capacitance. In real case, cabling is also distributed longitudinal inductance. This inductance is a part of a resonant circuit, due the PV generator system may be work such as active unintended antenna [4].

There are two types of disturbances: common mode (CM) disturbance and differential mode (DM) disturbance. DM disturbances cause radio frequency currents in an antiparallel way; CM disturbance cause radio frequency in a parallel way. Therefore, two types of active unintended antenna are presented in power plant [4]:

- Beverage antenna (common mode disturbance);

- Loop antenna (differential mode disturbance).

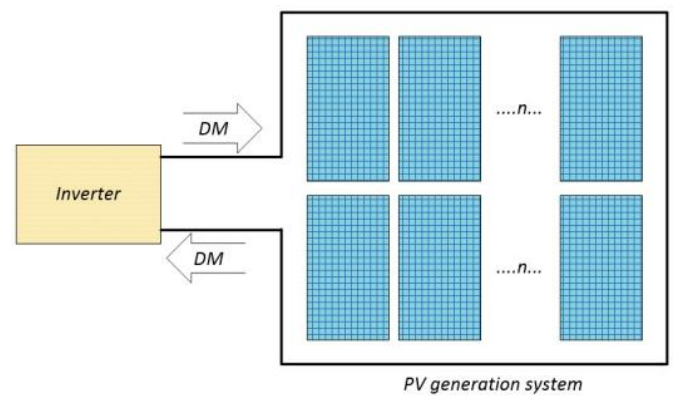

Fig. 2. PV-system to antenna approach (Differential mode)

Fig. 2 and Fig. 3 shown diagrams of antennas and how current flows through DC-side between PV generator system and inverter [9].

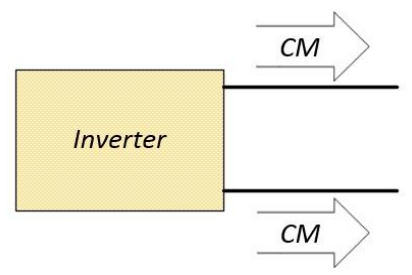

Fig. 3. PV-system to antenna approach (Common mode).

For determining electromagnetic field produced by DM voltages of PV generator system the equivalent circuit of solar cell is necessary. Equivalent circuit for c-Si cell is shown on Fig. 4 [13].

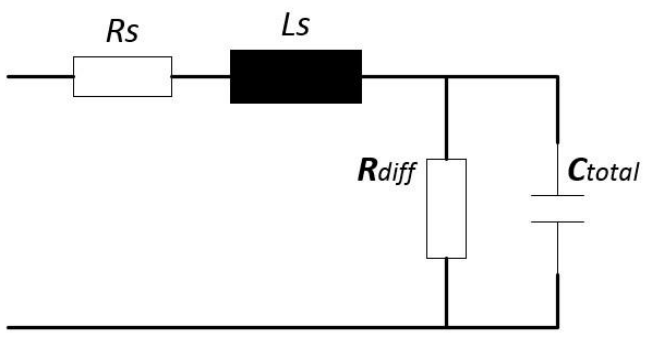

Fig. 4. Equivalent circuit of c-Si PV cell.

TABLE IV: EARTH CAPACITANCE FOR UNGROUNDED SYSTEMS [11]

\begin{tabular}{|l|l|}
\hline Conditions & $f=100 \mathrm{kHz}$ \\
\hline$C_{\text {total }}$ & $10 \mu \mathrm{F}$ \\
\hline$R_{\text {diff }}$ & $10 . .400 \mathrm{mOhm}$ \\
\hline
\end{tabular}

The values of equivalent scheme's resistors and capacitors are depending on the parameters of cell. Inductance $L_{s}$ primarily is determined by the geometry of cell connection. The impedance of $R_{s}$ element $R_{\text {diff }} \| C_{\text {total }}$ depends on many factors. These factors are: cell's voltage, solar irradiation, temperature and frequency [13]. For $100 \mathrm{~cm}^{2}$-cell the series resistor is constant and typically about $10 \mathrm{mOhm}$. For cell's voltage between $350-450 \mathrm{mV}$, irradiation between $500-1000$ $\mathrm{W} / \mathrm{m}^{2}$, frequency around $100 \mathrm{kHz}$ and temperature between $30-75^{\circ} \mathrm{C}$ values of $C_{\text {total }}$ and $R_{\text {diff }}$ are shown in Table IV [9] [11].

Impedance of $R_{\text {diff }} \| C_{\text {total }}$ element decreases as frequency increases. Therefore, in frequency range $150 \mathrm{kHz}-30 \mathrm{MHz}$ only series resistance and inductance might be taking into account [12]. Equivalent circuit of solar cell for this frequency range is shown on Fig. 5 [9].

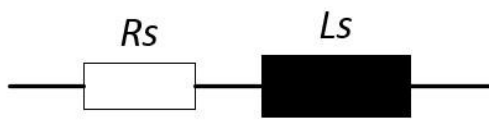

Fig. 5. Equivalent circuit for c-Si PV cell for $150 \mathrm{kHz}-30 \mathrm{Mhz}$ frequency range.

For CM disturbances loop is formed by parasitic earth capacitances. These capacitances are from cables to ground and from PV panels to ground. DM loop is formed by series resistances of solar cells. However, both the CM and DM disturbances are also determining by the switching actions and clock signals of the inverts. 


\section{Switching Devices}

In order to ensure the reliability of real-time operation of power systems in renewable energy microgrid, electromagnetic compatibility can not be neglected. This is because all electronics and major electronic components are subject to conducted and radiated noise [14]. Through analysis and study of electromagnetic compatibility are considered the phenomena described as [15], [16]: i. off- state output capacitance; ii. turn-on and turn-off; iii.. diode reverse recovery [17].

Electromagnetic interference (EMI) generated by switching devices (which are used in power processing circuits in phovoltaic plant for isolated or connected to utility configurations) cause disturbance in electronic equipment. Those disturbances are classified in conducted EMI $(150 \mathrm{kHz}$ to $30 \mathrm{MHz}$ ) and EMI irradiated (30 $\mathrm{MHz}$ to $1 \mathrm{GHz}$ ), due to the rapid switching [18].

The converters commercially available generally use IGBT with an antiparallel diode as electronic switch. In Fig. 6 (a) is shown a combination of all the capacitances described in different studies in order to gain a generalized model that can integrate all the capacitive and inductive couplings [16].

In the Fig. 6(b) it has been the case for the drive in Tri-level typology, where it is necessary to include the mounting diodes and their parasitic elements.

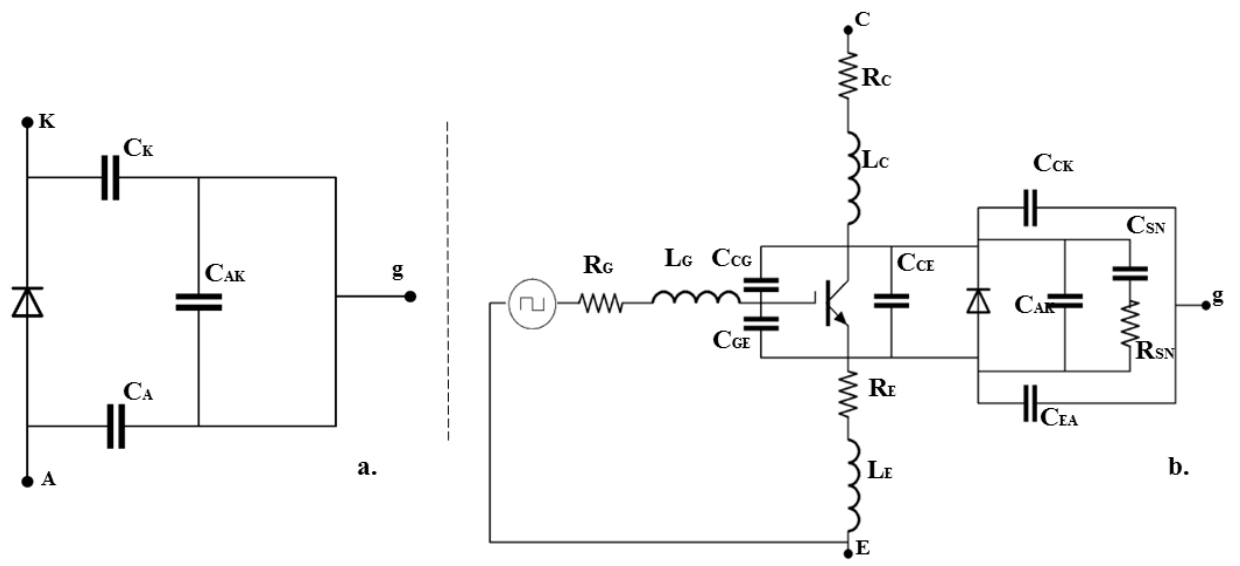

Fig. 6. Representatio of stray elements in switching devices. a. on antiparallel diodo. B. three-level topology of IGBT.

The variations produced by ultrafast PWM inverter output voltage (Phase Width Modulation) are responsible for several problems in EMC range. In photovoltaic systems, the common mode voltage produced by the inverter produces a rapid $d v / d t$ that excites all capacitances of system devices to ground, which creates undesirable high frequency currents in different routes [16].

Those currents can generate electromagnetic interference conducted, among other problems. Through the loops in which such currents it is included the capacitive coupling between: 1. solar cells and the corresponding module frame; 2 . the cable phase conductors and the tray or metal tubes and the corresponding module frame; 3. internal parts of the transformer and filter and its frame; 4. the internal inverter devices and the grounded heatsink. Many causes of EMI generation are as follows: PWM strategy, parasitic element, couplings in system, printed circuit board (PCB) and etc. According to their operation principle, there are three categories of PV inverters [19]-[21].

Off-Grid inverters. They can be used to convert DC power stored in batteries to $\mathrm{AC}$ power. For these applications, the adoption battery controller becomes necessary, in order to control the charging power supply to the battery. According to their delivered output waveforms, Off-Grid inverters belong to three classes: square wave, modified square wave and sine wave [22].

Grid-tied inverters. They are used to convert the DC power output of a PV generator to AC power for home or to be sold to the utility grid. Hence, they must deliver a pure sine wave, in-phase with the grid. A power system with this type of inverter uses the grid as a storage battery [22].

Hybrid inverters. Which perform both functions, they can operate as an Off-Grid inverter and as an Grid-Tied inverter at the same time. They allow selling excess power to the utility, also maintaining a battery bank for standby power in the event of a grid power failure. In a typical configuration, the hybrid inverter is connected to a battery bank, the utility power lines, a standby generator and the house load center [22].

\section{EMC MEASUREMENT SET-UP}

EMC comprehensive test have been performed at several PV generation systems with Grid-Tied, Off-Grid and Hybrid applications. The following categories of electromagnetic disturbances can be identified:

Radiated disturbances. Concerning the evaluation of radiated disturbances, as a general rule computation (simulation) is not recommended, since results are not reliable (in practical situations, the level of interference is strongly modified by a different arrangement of cables, equipment and/or the presence of other equipment in the vicinity). Hence, the only mean to evaluate radiated disturbances it is through measurements by measurement [4], [6], [23].

Conducted disturbances. Galvanic coupling of the inverter via AC mains may equally cause problems. EMC filters can be employed to reduce conducted disturbances and thus ensure clean operation of other equipment powered from the same AC mains. Place filters as close as possible to the inverter and ensure them a high-quality ground connection [4], [6], [23]. 
In order to investigate further the $\mathrm{CM}$ and $\mathrm{DM}$ noises generated by the radiated and conducted disturbances to the emission limits of Brazil the EMI measurement was performed at the semi-anechoic chamber of the $\mathrm{CPqD}$ Campinas, according CISPR 22 and 442 ANATEL standards.

The standard CISPR 22 establishes requirements for the radio disturbance emission and measurement methods in order to avoid radio interference, including data processing equipment, office machines, electronic business equipment and telecommunication equipment. The measures performed were considering the class $\mathrm{B}$, intended primarily for use in the home and include:

- it includes equipment with no fixed place of use: portable and telecommunications terminal equipment and personal computers;

- home environment, where the use of radio and television receivers may be at a distance of 10 meters from the unit responsible for electromagnetic disturbance.

There are three types of commonly used detectors in radio frequency emissions measurements: peak, quasi-peak and average. A peak detector responds almost instantaneously to the peak value of the signal and discharges. If the receiver resides on a single frequency, the output of the peak detector will follow the signal envelope (apparent contour signal formed by successive peak values). Since the peak detector has a very fast response is suited for diagnostics and rapid tests. In the following figures (conducted noise tests) is represented with blue values. The quasi-peak detector is a peak detector with moderate charge and discharge times. This detector is designed and recommended for common use by CISPR since it has been observed that by weighting the peak detector time constants, a better correlation could be found between the readings of the EMI receiver and transmit disturbance heard by the human ear. In the following figures (conducted noise tests) is represented with green values.

The standard 442 ANATEL establishes the requirements for the emission of electromagnetic interference applicable to equipment subject to mandatory certification. In the case of equipment using radio spectrum, requirements for electromagnetic interference radiated emission are described in this regulation and apply in the absence of specific requirements. Immunity to electromagnetic interference requirements apply to equipment classified as telecommunications products. The measures were carried out considering the category I and category II:

- category I: equipment and terminals for use by the general public to access the telecommunications service of collective interest;

- category II: not included in category I definition but makes use of radio spectrum, including antennas and radio equipment.

The measurement of the conducted EMI noise was performed with the following equipment, according CISPR 22 and 442 ANATEL standards:

- current source and DC voltage source;

- hardware setup: CE 8126 Schuko SN 457;

- measurement type: 2 line LISN;

- limit line \#1: 442 ANATEL - voltage on mains QP - class B;

- limit line \#2: 442 ANATEL - voltage on mains AV - class $\mathrm{B}$;
- frequency range: $150 \mathrm{kHz}-30 \mathrm{MHz}$;

- graphics level range: $0 \mathrm{~dB} \mu \mathrm{V}-80 \mathrm{~dB} \mu \mathrm{V}$.

The measurement of the radiated EMI noise was performed with the following equipment, according CISPR 22 and 442 ANATEL standards:

- current source and DC voltage source;

- hardware Setup: EMI radiatedLRE3m - PF1 - [EMI radiated;

- biconilog antenna and antenna tower: EMCO 2090 antenna tower [EMCO 2090 Antenna tower] @ GPIB0 (ADR 8);

- frequency range: $30 \mathrm{MHz}-1 \mathrm{GHz}$;

- graphics level range: $10 \mathrm{~dB} \mu \mathrm{V} / \mathrm{m}-55 \mathrm{~dB} \mu \mathrm{V} / \mathrm{m}$.

\section{ANALYSIS AND DISCUSSION OF RESULTS}

EMC evaluation was performed for the operating conditions Grid-Tied and Off-Grid.

TABLE V: GRID-TIED COMPONENTS SPECIFICATIONS

\begin{tabular}{|c|c|}
\hline \multicolumn{2}{|c|}{ Inverter } \\
\hline \multicolumn{2}{|c|}{ DC data } \\
\hline Maximum PV power & $1800 \mathrm{~W}$ \\
\hline DC voltage operation range & $125 \sim 400 \mathrm{~V}$ \\
\hline DC voltage starting & $125 \mathrm{~V}$ \\
\hline DC current maximum & $12 \mathrm{~A}$ \\
\hline \multicolumn{2}{|c|}{ AC data } \\
\hline AC nominal power & $1500 \mathrm{~W}$ \\
\hline Maximum CA power & $1650 \mathrm{~W}$ \\
\hline AC voltage rated input & $220 \mathrm{~V}$ \\
\hline AC current maximum & $8 \mathrm{~A}$ \\
\hline Maximum efficiency & $97.0 \%$ \\
\hline \multicolumn{2}{|c|}{ EMC Certifications } \\
\hline \multicolumn{2}{|c|}{ EN 61000-6-1, EN 61000-6-2, EN61000-6-3, EN61000-6-4 } \\
\hline \multicolumn{2}{|c|}{ String-Box } \\
\hline \multicolumn{2}{|c|}{ DC side } \\
\hline Fuse & $1000 \mathrm{VDC}$ \\
\hline DC surge protection & $1000 \mathrm{VDC}$ \\
\hline Disconnect switch & 600 VDC@32A \\
\hline \multicolumn{2}{|c|}{ AC side } \\
\hline AC surge protection & 275 VAC-50kA \\
\hline Disconnect switch & 275 VAC@20A \\
\hline
\end{tabular}

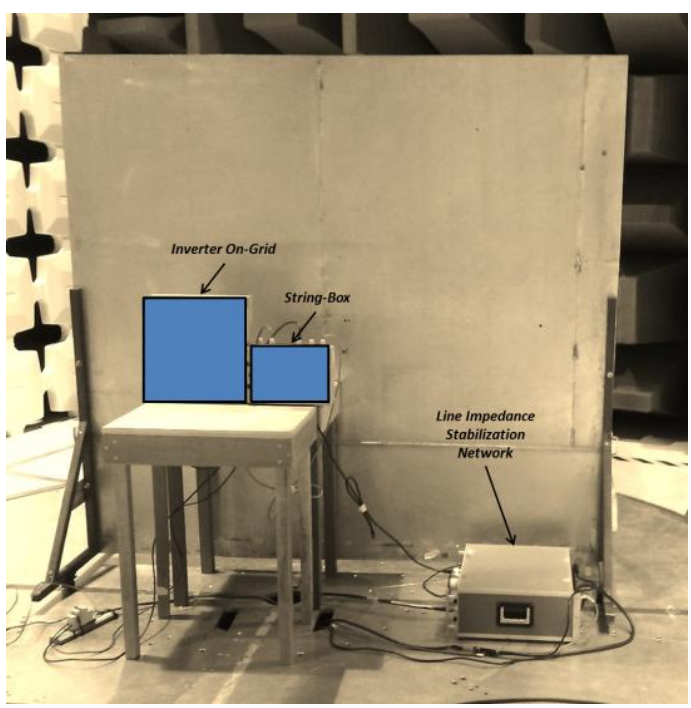

Fig. 7. Illustration of Grid-Tied set-up.

\section{A. GRID-TIED}

The Grid-Tied set-up was performed with one inverter and one string-box, the Table $\mathrm{V}$ and Fig. 7 shows the specifications, respectively. 
The corresponding result of the conducted EMI noise is shown in Fig. 8.

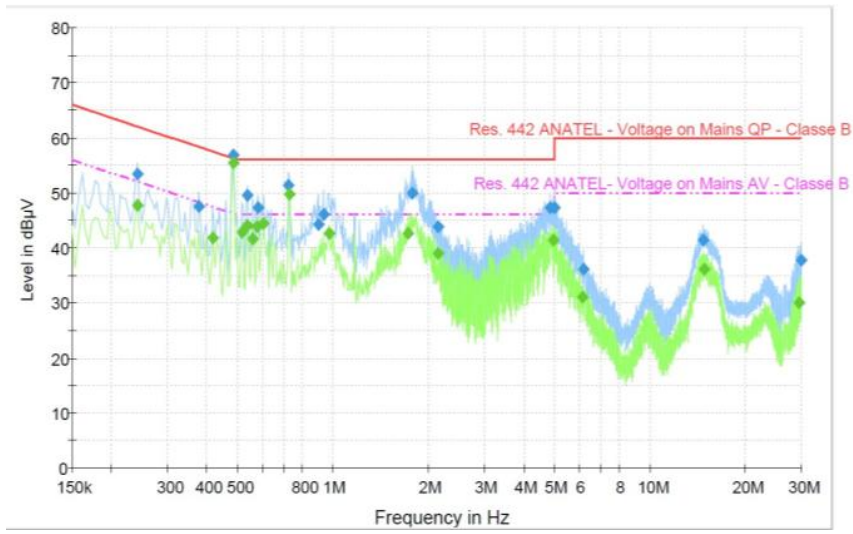

Fig. 8. Ambient conducted EMI noise at the Grid-Tied set-up.

The graph of Fig. 8 shows the conducted EMI noise behavior to a condition of 240VDC input - 220VAC output. The noise remains below the limits allowed by the standard in much of the spectrum frequency bands. However, there are some peaks in the frequency bands from $400 \mathrm{kHz}$ to $500 \mathrm{kHz}$ it is exceeded the limits of the standard. The measurements of this setup also were performed to conditions of 127VDC input - 220VAC output and 400VDC input - 220VAC output. The similar profile was observed to conducted EMI noise of this conditions.

In the second part of the Grid-Tied test the measurement of radiated EMI noise was performed. The corresponding result is shown in Fig. 9.

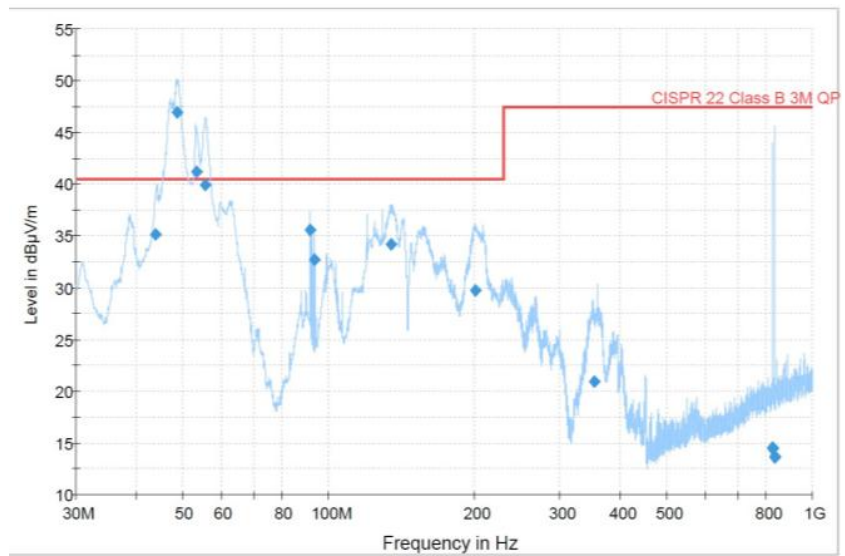

Fig. 9. Ambient radiated EMI noise at the Grid-Tied setup.

The graph of Fig. 9 shows the radiated EMI noise behavior to a condition of 240VDC input - 220VAC output. The noise remains below the limits allowed by the standard in much of the spectrum frequency bands. However, there are some peaks in the frequency bands from $45 \mathrm{MHz}$ to $58 \mathrm{MHz}$ it is exceeds the limit of the standard. The measurements of this setup also were performed to conditions of 127VDC input 220VAC output and 400VDC input - 220VAC output. The similar profile was observed to radiated EMI noise of this conditions. Particularly, in this case, a pulse of electromagnetic disturbance was captured by the antenna, frequency band of about $850 \mathrm{MHz}$, probably a device around the test site, and that influenced the results of the measurements.

\section{B. OFF-Grid}

The Off-Grid set-up was performed with one inverter, one string-box, one battery controller, two batteries and one heating (load), the Table VI and Fig. 10, shows the specifications, respectively.

TABLE VI: STRING-BOX SPECIFICATIONS

\begin{tabular}{|c|c|}
\hline \multicolumn{2}{|c|}{ Inverter } \\
\hline \multicolumn{2}{|c|}{ DC data } \\
\hline \multicolumn{2}{|l|}{ Maximum DC power } \\
\hline DC voltage rated input & $24 \mathrm{~V}$ \\
\hline DC current maximum & $60 \mathrm{~A}$ \\
\hline \multicolumn{2}{|c|}{ AC data } \\
\hline AC nominal power & $1400 \mathrm{~W}$ \\
\hline AC voltage & $127 \mathrm{~V}$ \\
\hline $\mathrm{AC}$ current maximum & $60 \mathrm{~A}$ \\
\hline Maximum efficiency & $92.0 \%$ \\
\hline \multicolumn{2}{|c|}{ EMC Certifications } \\
\hline \multicolumn{2}{|c|}{ Not certified } \\
\hline \multicolumn{2}{|c|}{ String-Box } \\
\hline \\
\hline \multirow{2}{*}{\multicolumn{2}{|c|}{$\begin{array}{l}\text { Fuse } \\
\text { DC Surge protection }\end{array}$}} \\
\hline & \\
\hline Disconnect switch & 600 VDC@32A \\
\hline \multicolumn{2}{|c|}{ AC side } \\
\hline AC Surge protection & $275 \mathrm{VAC}-50 \mathrm{kA}$ \\
\hline Disconnect switch & 275 VAC@20A \\
\hline \multicolumn{2}{|c|}{ Battery Controller Specifications } \\
\hline Maximum PV power & $1400 \mathrm{~W}$ \\
\hline DC voltage operation range & $15 \sim 145 \mathrm{~V}$ \\
\hline DC voltage rated input & $24 \mathrm{~V}$ \\
\hline \multirow{2}{*}{$\begin{array}{r}\text { DC current maximum } \\
\text { Battery Spe }\end{array}$} & $64 \mathrm{~A}$ \\
\hline & tions \\
\hline \multicolumn{2}{|c|}{\begin{tabular}{l|l} 
& $12 \mathrm{~V} 84 \mathrm{Ah}, \mathrm{C} 1025^{\circ} \mathrm{C}$ \\
\end{tabular}} \\
\hline \multicolumn{2}{|c|}{ Heating (load) Specifications } \\
\hline Maximum power & $1500 \mathrm{~W}$ \\
\hline AC voltage & $127 \mathrm{~V}$ \\
\hline
\end{tabular}

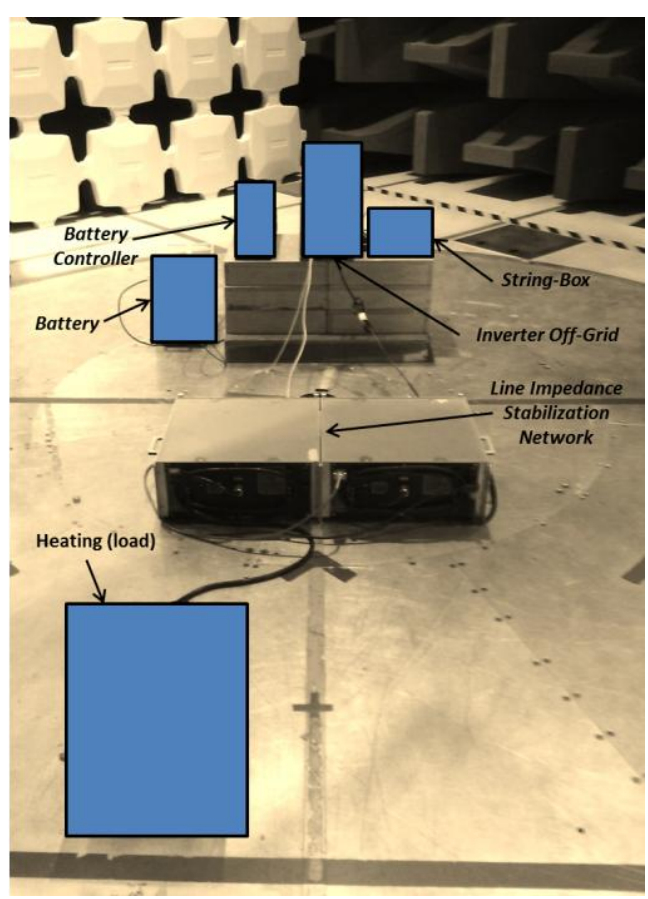

Fig. 10. Illustration of Off-Grid set-up.

The first operation mode of the Off-Grid set-up was analyzed it is the battery power supply to the load. The corresponding result is shown in Fig. 11.

The graph of Fig. 11 shows the conducted EMI noise behavior at the battery power supply to the load to a condition 
of 24VDC input - 127VAC output. The noise exceeded the limits of the standard in much of the spectrum frequency bands, mainly from $150 \mathrm{kHz}$ to $5 \mathrm{MHz}$. There are some peaks in the frequency bands from $5 \mathrm{MHz}$ to $16 \mathrm{MHz}$ and from $24 \mathrm{MHz}$ to $26 \mathrm{MHz}$ which the noise remained below the standard limits.

The second operation mode of the Off-Grid setup was analyzed it is the AC generator (AC source auxiliary) supplying power to recharge batteries. The corresponding result is shown in Fig. 12.

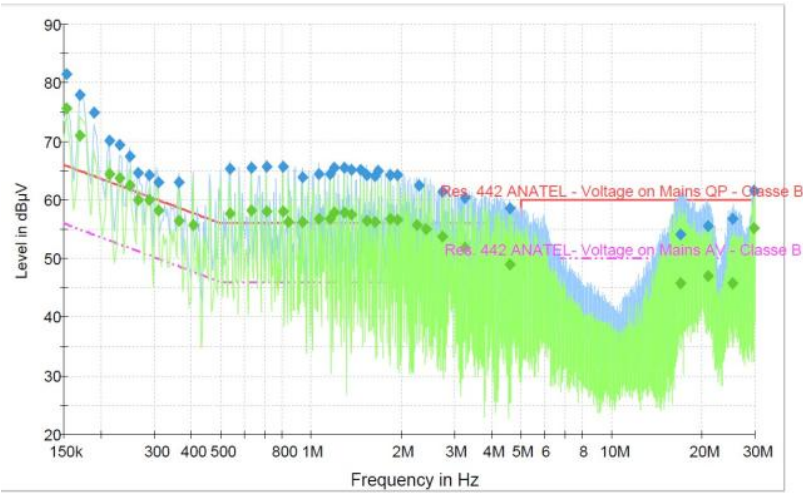

Fig. 11. Ambient conducted EMI noise at the battery power supply to the load.

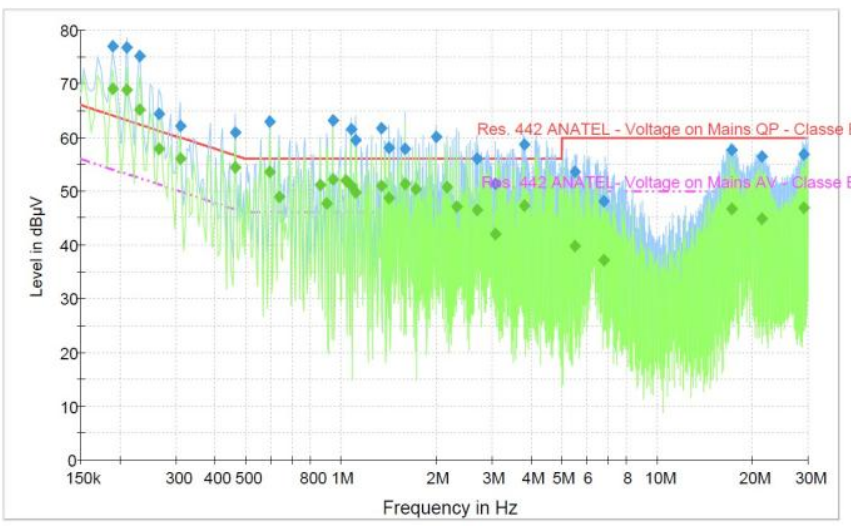

Fig. 12. Ambient conducted EMI noise at the AC generator (AC source auxiliary) supply power to recharge batteries.

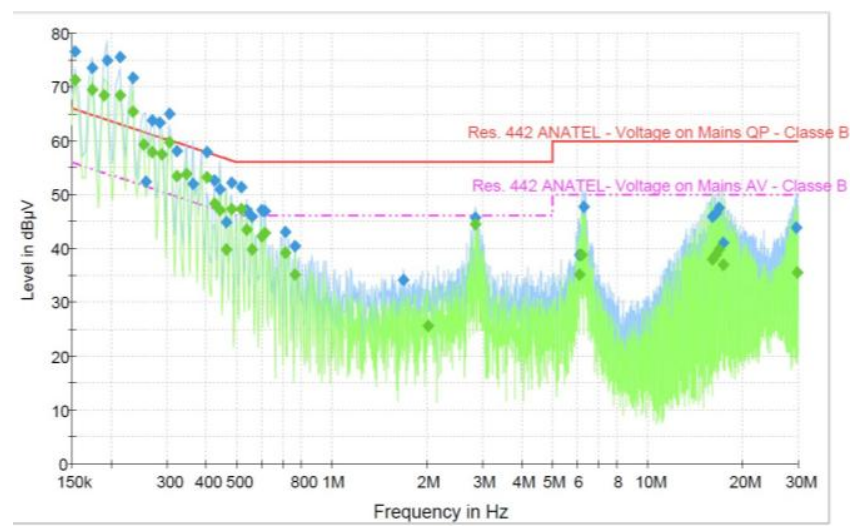

Fig. 13. Ambient conducted EMI noise at the power supply from the AC generator (AC source auxiliary) to load.

The graph of Fig. 12 shows the conducted EMI noise behavior at the AC generator (AC source auxiliary) supply power to recharge batteries to a condition of 127VAC input 24VDC output. The noise exceeded the limits of the standard in much of the spectrum frequency bands, mainly from $150 \mathrm{kHz}$ to $5 \mathrm{MHz}$. There are some peaks in the frequency bands from $5 \mathrm{MHz}$ to $30 \mathrm{MHz}$ which the noise remained below the standard limits.

The third operation mode of the Off-Grid setup was analyzed it is the power supply from the $\mathrm{AC}$ generator (AC source auxiliary) to load. The corresponding result is shown in Fig. 13.

The graph of Fig. 13 shows the conducted EMI noise behavior the AC generator (AC source auxiliary) to load to a condition of 127VAC input - 127VAC output. The noise exceeded the limits of the standard only a small frequency band of the spectrum, mainly from $150 \mathrm{kHz}$ to $400 \mathrm{kHz}$. For the remaining spectrum frequency bands, the noise remains below the standard limits.

The fourth operation mode of the Off-Grid setup was analyzed it is the DC source supplying power to the batteries and the batteries supplying power to the load. The corresponding result is shown in Fig. 14.

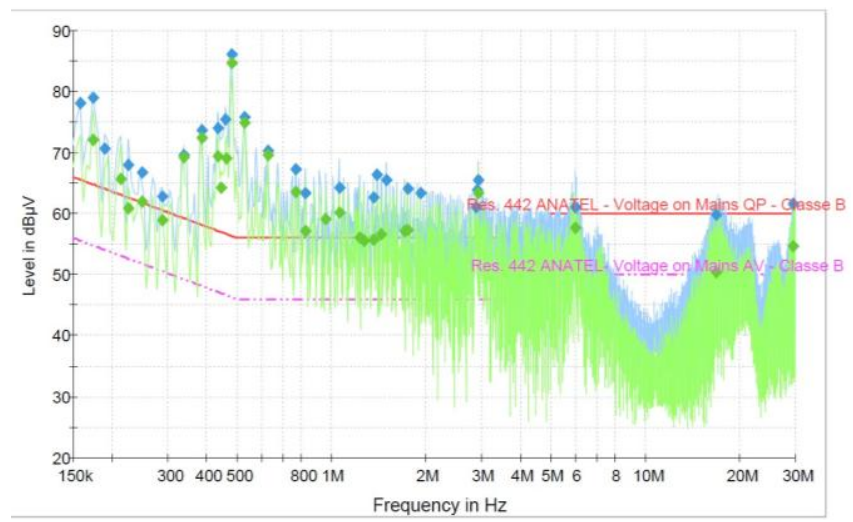

Fig. 14. Ambient conducted EMI noise at the DC source supply power to the batteries and the batteries supply power to the load.

The graph of Fig. 14 shows the conducted EMI noise behavior at the DC source supply power to the batteries and the batteries supply power to the load to a condition of 80VDC (PV generation system) - 24VDC input - 127VAC output. The noise exceeded the limits of the standard in much of the spectrum frequency bands, mainly from $150 \mathrm{kHz}$ to $6 \mathrm{MHz}$. There are some peaks in the frequency bands from $7 \mathrm{MHz}$ to $15 \mathrm{MHz}$ and from $19 \mathrm{MHz}$ to $26 \mathrm{MHz}$ which the noise remained below the standard limits. The measurements of this setup also was performed to conditions of 130VDC (PV generation system) - 24VDC input - 127VAC output. The similar profile was observed to conducted EMI noise of this conditions.

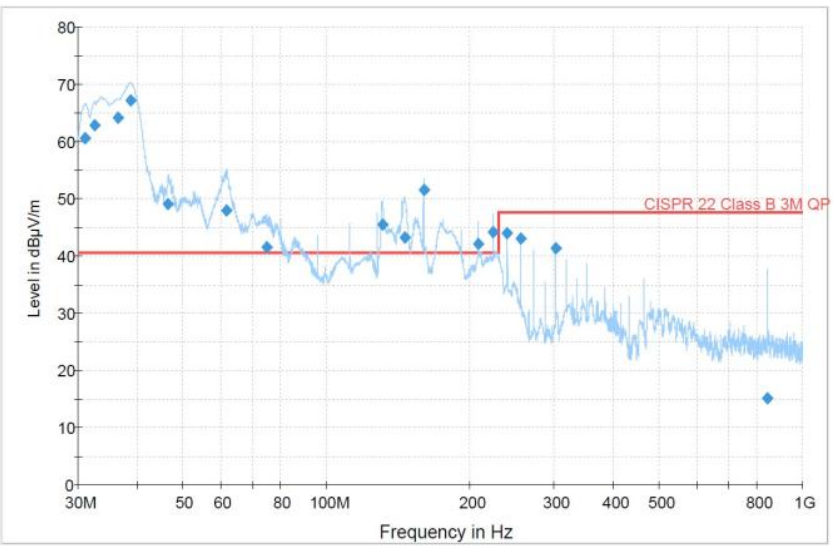

Fig. 15. Ambient radiated EMI noise at the Off-Grid set-up.

In the second part of the Off-Grid test the measurement of 
radiated EMI noise was performed. The corresponding is shown in Fig. 15.

The graph of Fig. 15 shows the radiated EMI noise behavior, for the operation mode where the DC source supply power to the battery and the batteries supply power to the load to a condition 80VDC (PV Generation system) - 24VDC input - 127VAC output (we opted for this mode of operation due to operability of all components involved). The noise exceeded the limits allowed by the standard in the spectrum frequency bands, mainly from $30 \mathrm{MHz}$ to $80 \mathrm{MHz}$ and from $140 \mathrm{MHz}$ to $190 \mathrm{Mhz}$. However, there are some peaks in the frequency bands from $90 \mathrm{MHz}$ to $130 \mathrm{MHz}$ and from $200 \mathrm{MHz}$ to $1 \mathrm{GHz}$ which the noise remained below the standard limits. The measurements of this setup also was performed to conditions of 130VDC (PV Generation system) - 24VDC input - 127VAC output. The similar profile was observed to radiated EMI noise of this conditions. Particularly, in this case, the same pulse of electromagnetic disturbance observed in Fig. 9 , was captured by the antenna, frequency band of about $850 \mathrm{MHz}$, probably a device around the test site, and that influenced the results of the measurements.

\section{CONCLUSION}

This paper sought to demonstrate the importance of proposing specific standards and mandatory certification of EMC for PV generation systems components, mainly PV inverters. The results of Off-Grid set-up showed that for an environment with conducted EMI noise the frequency spectrum band from $150 \mathrm{kHz}$ to $5 \mathrm{MHz}$, and for an environment with radiated EMI noise the frequency spectrum band from $30 \mathrm{MHz}$ to $200 \mathrm{MHz}$ it is more affected. Particularly the results of Off-Grid set-up show that the intensity of the noise depends on the operating mode when the PV inverter performs switching the frequency of the noise increases significantly. The results of Grid-tied set-up show better results, only in some peaks in the frequency bands from $400 \mathrm{kHz}$ to $500 \mathrm{kHz}$ for conducted EMI noise and from $45 \mathrm{MHz}$ to $58 \mathrm{MHz}$ for radiated EMI noise it is exceeded the limits of the standard, however the concern is greater since the equipment used for the tests has EMC certifications.

It is evident in this work the need to create mandatory requirements for certification and EMC testing for PV generation systems since its popularization and consequent implementation will be in the form of integrated kits for small residential installers that can often inadvertently cause interferences in the vicinity. The requirements should include qualification and standardization of EMC in PV generation systems as well as an accurate assessment of risks as other services such as radio, TV, 3G, 4G, Wi-Fi, Bluetooth and others. In larger facilities as PV generation plants throughout a work must be developed because the order of magnitude of the powers involved are much greater and also integration with the system of SPDA of the entire complex to the same operate without risk.

Considering the previous analysis, it follows that mounting of a PV generation system according to EMC compliance is paramount. Here are summarized some guidelines to minimize interference in facilities:
- Locate the PV inverter as far as possible from appliances that are susceptible to interference;

- Install the right EMC filters for disturbance suppression on AC side of the PV inverter and place them as close as possible to PV inverter;

- The cables between PV inverter and filter and also between PV inverter and PV generator system must be kept well separated from the AC mains supply cables to the input of the filter;

- The filter must be mounted as close as possible from PV inverter, in order to shorten the cable connecting them (this cable acts as an antenna, radiating disturbances).

- Install both PV inverter and filter in the electrically shielded metal wiring cabinet;

- To balance the configuration and reduce radiation, use twisted shielded pairs to connect the PV inverter to the PV panel. Connect the shield to the ground. Since one conductor of the pair is used for return, the shield itself does not transport net current and contamination is avoided;

- Provide a low-impedance signal ground (equally called EMC ground), distinct from the safety ground (protective earth) that is effective only to protect humans against electrocution.

\section{ACKNOWLEDGEMENTS}

The authors would like to thank the Instituto Federal de Educação, Ciência e Tecnologia do Sul de Minas (IFSULDEMINAS), Coordenação de Aperfeiçoamento de Pessoal de Nivel Superior (CAPES), the Conselho Naional de Desenvolvimento Científico e Tecnológico (CNPq), the Fundação de Amparo à Pesquisa do Estado de São Paulo (FAPESP), the Departamento de Comunicações (DECOM), the Faculdade de Engenharia Elétrica e de Computação (FEEC), and the Universidade Estadual de Campinas (UNICAMP), for their support in the development of this research.

The authors would like to thank the Centro de Pesquisa e Desenvolvimento em Telecomunicações (CPqD) in special Dr. Vitor Velanno for their valuable contribution to this Research, and, Prof. Yuzo Iano by the guidance and valuable contribution in the elaboration of this work.

\section{REFERENCES}

[1] S. R. Bull, "Renewable energy today and tomorrow," IEEE, vol. 89, no. 8, pp. 1216-1226, 2001.

[2] V. Quaschning, Understanding Renewable Energy Systems, vol. 67 London: Carl Hanser Verlag GmbH \& Co KG, 2010.

[3] M. C. Di Piazza, C. Serporta, G. Tine, and G. Vitale, "Electromagnetic compatibility characterisation of the DC side in a low power photovoltaic plant," in Proc. 2004 IEEE Int. Conf. Ind. Technol., 2004, vol. 2.

[4] R. Araneo, S. Lammens, M. Grossi, and S. Bertone, "EMC issues in high-power grid-connected photovoltaic plants," IEEE Trans. Electromagn. Compat., vol. 51, no. 3, part 2, pp. 639-648, 2009.

[5] J. F. Dawson, A C. Marvin, and C. A Marshman, "Electromagnetic compatibility," Ind. Electron., vol. 10, p. 50, March 2002.

[6] T. Degner, W. Enders, A. Schülbe, H. Daub, and A. Schiilbe, "EMC and safety design for photovoltaic systems (ESDEPS)," Eur. Sol. Energy Conf. Exhib., no. 1, pp. 1-5, 1999.

[7] H. W. Ott, Electromagnetic Compatibility Engineering, 2009.

[8] C. A. Balanis, "Antenna theory: a review," IEEE, vol. 80, no. 1, 1992.

[9] Y. Smirnov, "Rf disturbances produced by high-power photovoltaic solar plants," Lappeenranta University of Technology, 2011. 
[10] D. M. Powell, M. T. Winkler, A. Goodrich, and T. Buonassisi, "Modeling the cost and minimum sustainable price of crystalline silicon photovoltaic manufacturing in the united states," IEEE $J$. Photovoltaics, vol. 3, no. 2, pp. 662-668, 2013.

[11] R. Struzak, "Basic antenna theory," International Cente for Theoretical Physics ICTP, 2007.

[12] N. Henze, G. Bopp, T. Degner, H. Häberlin, and S. Schattner, "Radio interference on the DC side of PV systems: Research results and limits of emission," in Proc. 17th EU PV Conf, pp. 22-25, October 2001.

[13] S. Schattner, G. Boop, R. Fisher, H. Haeberlin, R. Minker, R. Venhuizen, and B. Verhoeven, "A new measurement technique ensuring the EMC of photovoltaic systems," in Proc. 2001 14th EMC Zurich Symposium, 2001.

[14] B. Zhu, D. Leskarac, J. Lu, and M. Wishart, "Electromagnetic interference investigation of solar pv system for microgrid structure," in Proc. 7th Asia Pacific International Symposium on Electromagnetic Compatibility, 2016, pp. 456-459.

[15] H. Zhang, S. Wang, and J. Puukko, "Common mode EMI noise modeling and prediction for a three-phase, three-level, grid tied photovoltaic inverter," in Proc. 7th Asia Pacific International Symposium on Electromagnetic Compatibility, 2016, pp. 1188-1194.

[16] P. Pereira, H. De Paula, B. De Jesus Cardoso Filho, and J. A. De Souza Brito, "Photovoltaic systems representation for high frequency studies - Part I: The power transformer modeling," in Proc. 2015 IEEE 13th Brazilian Power Electron. Conf. 1st South. Power Electron. Conf. COBEP/SPEC 2016, 2016.

[17] O. Ceaki, R. Vatu, and M. Mancasi, "Analysis of electromagnetic disturbances for grid- connected PV plants," Modern Electric Power Systems, pp. 1-5, 2015.

[18] K. Rajkumar, B. Karthikeyan, and S. Senthilkumar, "An overview of conducted EMI and its mitigation in photovoltaic systems An overview of conducted EMI and its mitigation in photovoltaic systems," Int. $J$. Appl. Eng. Res., vol. 10, pp. 23523-23534, January 2015.

[19] D. Hamza and P. Jain, "Conducted EMI in grid-tied PV system," in Proc. INTELEC, International Telecommunications Energy Conference, 2010.

[20] J. Rajamaki, "Correlations between EMI statistics and EMC market surveillance in Finland," in Proc. 2004 Int. Symp. Electromagn. Compat., 2004, vol. 2.

[21] J. Rajamaki, "Finnish safety and EMC market surveillance statistics," in Proc. 2002 IEEE Int. Symp. Electromagn. Compat., vol. 2, 2002.

[22] A. U. Schmiegel and A. Kleine, "Optimized Operation strategies for pv storages systems yield limitations, optimized battery configuration and the benefit of a perfect forecast," Energy Procedia, vol. 46, pp. 104-113, 2014.

[23] J. Kirchhof and Y. Zhang, "A new EMC DC Line Impedance Stabilization Network," in Proc. 26th European Photovoltaic Solar Energy Conference and Exhibition, 2011, pp. 1-4.

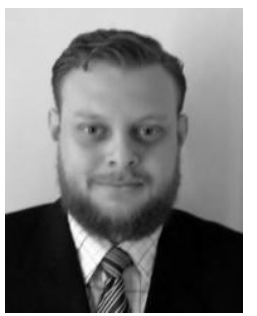

Hermes José Loschi graduated in control and automation engineering from Paulista University in 2014. Currently he is an M.Sc and PhD candidate in the Department of Communications, Faculty of Electrical and Computer Engineering at Unicamp. He has professional experience in the manufacturing processes of Diesel engine, in particular MTU and Mercedes. Currently he is a researcher at the Laboratory of Visual Communications (LCV). His main topics of interests are wireless sensor network, internet of things, smart grid, broadcasting, biomass, photovoltaic systems applications , solar energy and solar tracking.

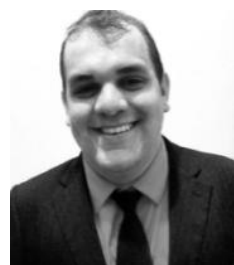

Luiz Antonio de Sousa Ferreira graduated in computer science from Pontifical Catholic University of Minas Gerais - PUC Minas in 2015. Currently he is an M.Sc candidate in the Department of Communications, Faculty of Electrical and Computer Engineering at Unicamp.

His research interests are wireless network, smart grid, photovoltaic systems applications, telecommunications, digital signal processing (image and video), digital TV, and HDTV.

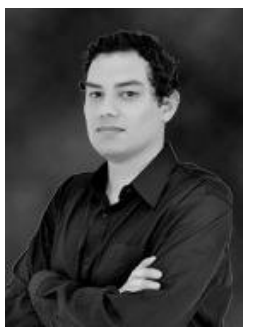

Douglas A. do Nascimento graduated in electrical engineering from University of Western Santa Catarina in 2015. Currently he is the M.Sc candidate in the Department of Communications, Faculty of Electrical and Computer Engineering (FEEC) at Unicamp. His research interests are signal processing, embedded systems, microelectronic systems, pattern recognizing and artificial intelligence.

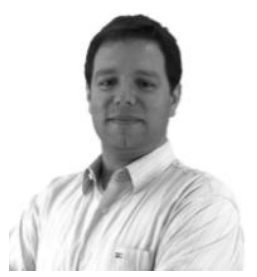

Paulo E. R. Cardoso holds a degree in electrical engineering from the FEEC-UNICAMP in 2002 and an MSc degree in electrical engineering (electronics) from DEMIC-FEEC-UNICAMP in 2005. He is currently a $\mathrm{PhD}$ candidate in the LCV-DECOM-FEEC-UNICAMP, searching digital TV. He licensed from the post of Specialist in regulating in the Agência Nacional de Telecomunicações - Anatel, where it operates in coordination of grants and resources to the provision, working with the licensing and amendment of technical characteristics of broadcasting stations. Previously, he served in the surveillance in broadcasters and in the solution of problems of radio interference in any system of telecommunication. He was responsible for the Technical Regulation to Broadcasting in Modulated Frequency and analysis of processes of technical feasibility for inclusion or amendment of the Basic Plan of Distribution Channels of Broadcasting in Modulated Frequency. He participated as an observer in the Federal Government in testing of Digital Radio Broadcasting, both in tests of American Standard - HD Radio, in 2008 and 2012, as in tests of the European standard - DRM, in 2010. He has worked as a telecommunications researcher of the Fundação Centro de Pesquisas e Desenvolvimento - $\mathrm{CPqD}$

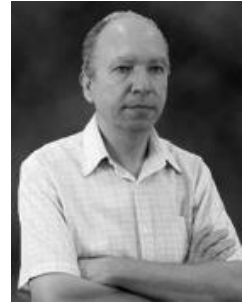

Silvio Renato Messias de Carvalho obtained his B.Sc degree in electrical engineering at UNICAMP in 1994; a MSc degree in 2007 and a $\mathrm{PhD}$ degree in 2013 in electrical engineering from UNICAMP as well.

His research interests are audio and video for digital TV, broadcast engineering, digital TV engineering, RF systems, mobile TV, antennas and energy efficiency.

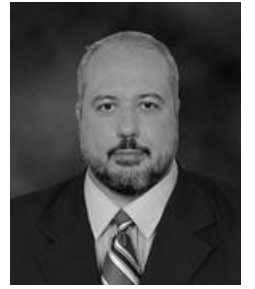

Fabrizzio Daibert Conte graduated in electrical engineering from Paulista University in 2012 Currently he is an M.Sc candidate at Decom/Feec/Unicamp, Department of Communications, School of Electrical and Computer Engineering, Campinas State University. His research interests are embedded systems, wireless network, internet of things, digital TV, broadcasting, cells and photovoltaic systems, energy

and solar tracking. 